\title{
PENYULUHAN PENGELOLAAN KEUANGAN DAN PERENCANAAN USAHA DI DESA BANI AMAS KECAMATAN BENGKAYANG
}

\author{
Sabinus Beni ${ }^{1}$, Blasius Manggu ${ }^{2}$, Yosua Damas Sadewo ${ }^{3}$ \\ ${ }^{1,3}$ Program Studi Kewirausahaan, STIM Shanti Bhuana, Jalan Bukit Karmel No.1 Bengkayang \\ ${ }^{2}$ Program Studi Manajemen, STIM Shanti Bhuana, Jalan Bukit Karmel No.1 Bengkayang \\ 1e-mail: beni@shantibhuana.ac.id
}

\begin{abstract}
Abstrak
Kegiatan pengabdian masyarakat ini dilakukan di Aula Kantor Desa Bani Amas Kecamatan Bengkayang Kalimantan Barat bagi keluarga pra sejahtera dan aparatur desa di Desa Bani Amas. Permasalahan utama yang dihadapi oleh mitra adalah kesulitan dalam mengelola keuangan keluarga, tidak adanya pemisahan keuangan untuk konsumsi dan tabungan keluarga serta kesulitan dalam merencanakan usaha yang sesuai dengan kondisi perekonomian mitra. Tujuan kegiatan adalah memberikan edukasi terhadap masyarakat keluarga penerima manfaat program keluarga harapan dalam mengelola keuangan dan menyusun rencana usaha. Metode kegiatan ini adalah dengan kegiatan penyuluhan tatap muka yang dilakukan selama satu hari efektif terbagi dalam empat sesi dan diakhiri dengan sesi tanya jawab dan evaluasi untuk mengetahui hasil kegiatan dalam mengatasi permasalahan mitra. Hasil kegiatan ini berdasarkan evaluasi diketahui bahwa sebanyak $71 \%$ atau 45 orang dari 64 orang peserta memahami materi dan siap menerapkannya dalam kehidupan sehari-hari terutama dengan menabung minimal $10 \%$ dari total penghasilan dan ingin membuka kebun, ada yang ingin membuka kebun jagung dan ada yang membuka kebun sayur. Sebanyak 19 orang tidak atau belum memahami, hal tersebut dikarenakan beberapa diantaranya masih ingin berada pada zona nyaman menerima bantuan pemerintah. Komitmen pemerintah Desa Bani Amas pada tahun 2021 untuk menganggarkan dari dana desa untuk kegiatan pemberdayaan pendampingan usaha produktif masyarakat.
\end{abstract}

Kata kunci: penyuluhan, perencanaan usaha, program keluarga harapan

\begin{abstract}
This Community Service activity is carried out in the Bani Amas Village Office Hall, Bengkayang District, West Kalimantan for Pre-Prosperous Families and Village Apparatuses in Bani Amas Village. The main problems faced by partners are difficulties in managing family finances, the absence of financial separation for family consumption and savings and difficulty in planning a business that is in accordance with the economic conditions of partners. The aim of the activity is to provide education to the community of the Family Hope Program Beneficiaries in managing finances and preparing business plans. The method of this activity is a face-to-face counseling activity carried out for one day effectively divided into four sessions and ended with a question and answer session and evaluation to find out the results of activities in overcoming partner problems. The results of this activity based on the evaluation revealed that as many as $71 \%$ or 45 people from 64 participants understood the material and were ready to apply it in daily life, especially by saving at least $10 \%$ of total income and wanting to open a garden, some who wanted to open a corn garden and there were others open a vegetable garden. As many as 19 people do not or do not understand, this is because some of them still want to be in the comfort zone to receive government assistance. The commitment of the village government of Bani Amas in 2021 to budget from the Village Fund for the empowerment of community productive business assistance activities.
\end{abstract}


Keywords: counseling, business planning, family hope program

\section{PENDAHULUAN}

Desa Bani Amas merupakan salah satu Desa yang berada di Kecamatan Bengkayang, berbatasan langsung dengan Desa Setia Budi, Kelurahan Sebalo, Kelurahan Bumi Emas Kecamatan Bengkayang, dan Kecamatan Teriak. Mayoritas masyarakat bekerja sebagai petani. Jarak tempuh dari Kampus STIM Shanti Bhuana menuju lokasi sekitar \pm 15 Menit melalui jalan darat. Angka kemiskinan di Kabupaten Bengkayang tahun 2019 sebanyak 17.490 orang atau sebesar $7.17 \%$ dari total penduduk dengan rata-rat pengeluaran penduduk miskin sebesar Rp339.891,- (BPS, 2019).

Permasalahan utama mitra khususnya Keluarga Penerima Manfaat (KPM) Program Keluarga Harapan ( $\mathrm{PKH})$ mengalami kesulitan dalam mengelola uang terutama uang bantuan PKH dan penghasilan yang didapatkan, selain itu mitra juga mengalami kendala dalam menyusun rencana keuang untuk mebuka usaha perkebunan jagung dan sayuran agar mereka memiliki pendapatan yang memadai dan lepas dari lingkaran kemiskinan serta masih belum adanya pemisahan keuangan yang menajdi bagain dari tabungan serta uang yang menjadi bagian dari konsumsi keluarga. Dengan adanya kegiatan penyuluhan ini diharapkan menjawab masalah yang dihadapi oleh mitra yang terlihat dari adanya anggaran belanja keluarga, pemisahan uang untuk tabungan dan uang untuk konsumsi serta adanya rencana usaha yang siap diimplementasikan berupa kebun jagung dan kebun sayur untuk meningkatkan pendapatan keluarga dan setelah itu peserta bisa mandiri dengan tidak lagi menerima bantuan PKH (Apolius, 2019).

Permasalah utama diadakannya kegiatan ini adalah terkait kendala keluarga pra sejahtera dalam pengelolaan keuangan keluarga. Hal ini membuat kondisi ekonomi keluarga tidak mengalami peningkatan taraf hidup. Permasalahan ini jika dibiarkan akan berdampak negatif bagi tujuan pembangunan. Kegiatan ini akan mencoba membantu melalui penyuluhan terkait literasi pengelolaan keuangan yang sederhana dan rencana usaha bagi Keluarga Pra Sejahtera dan Aparatur Desa Bani Amas. 
Tujuan dari pelaksanaan kegiatan ini adalah memberikan edukasi terhadap masyarakat Keluarga Penerima Manfaat (KPM) Program Keluarga Harapan dalam mengelola keuangan dan menyusun rencana usaha. Sedangkan manfaat dari kegiatan ini adalah agar Keluarga Pra Sejehatera (miskin) penerima bantuan Program Keluarga Harapan (PKH) dan Aparatur Desa di Desa Bani Amas dapat membuat Anggaran Belanja Keluarga (ABK) dan Perencanaan Usaha serta ABK dan rencana usaha dapat diterapkan dalam kehidupan sehari-hari dan terbebas dari lingkaran kemiskinan.

Program Keluarga Harapan (PKH) merupakan program pengentasan kemiskinan yang difasilitasi oleh Kementerian Sosial Republik Indonesia dengan memberikan bantuan tunai bersyarat dengan ketentuan Rumah Tangga Pra Sejahtera (disebut Keluarga Penerima Manfaat) yang memiliki anak usia sekolah dan bersekolah pada tingkat SD, SMP Sederajat, SMA/SMK Sederajat, memiliki Bayi dan Balita, Ibu Hamil, Lansia, dan Disabilitas berat. Dalam buku yang berjudul pembangunan manusia melalui credit union dan artikel tentang pengelolaan keuangan keluarga penerima manfaat program keluarga harapan mengungkapkan tentang pola pengelolaan keuangan keluarga (Beni, 2017).

Beberapa kunci untuk mengelola keuangan secara sederhana yang dapat diterapkan oleh masyarakat (Beni, 2016), yaitu: (1) Pahami portofolio keuangan keluarga Anda. Pahami bagaimana kondisi tabungan, jumlah tagihan yang harus dibayar setiap bulan baik untuk angsuran pinjaman, listrik, telepon (HP), servis motor, belanja, berobat dan undangan maupun arisan. (2) Susun anggaran belanja keluarga (ABK). Buatlah rencana anggaran keuangan dan belanja keluarga yang sebelumnya didiskusikan antar sesama anggota keluarga untuk diterapkan. Anggaran dibuat secara realistis dan tidak melebihi pemasukan yang ada setiap bulannnya. Anggaran dibuat secara rinci dan harus dipatuhi oleh seluruh anggota keluarga. (3) Bedakan antara kebutuhan dan keinginan. Beberapa praktek penerapan anggaran belanja keluarga selalu berbeda dengan yang telah disusun bersama anggota keluarga, hal ini terjadi karena saat berbelanja kita selalu terdorong untuk keluar dari daftar prioritas kebutuhan dan menuruti keinginan sesaat yang berakibat pada membengkaknya pengeluaran terutama untuk 
keperluan yang tidak mendesak atau tidak prioritas yang menjadikan pemasukan lebih kecil dari pada pengeluaran (Beni, Manggu, \& Sensusiana, 2018). (4) Hindari hutang yang tidak produktif. Adanya berbagai tawaran dan promosi membuat anggota keluarga terjebak untuk melakukan pinjaman untuk kegiatan yang tidak produktif, salah satunya adalah melakukan kredit untuk pembelian barang atau perabot rumah tangga karena adanya promosi dan belanja dengan sistem kredit serta mengajukan pinjmaman karena gengsi dan ikut-ikutan tetangga atau kenalan dengan iming-iming promosi kredit dngan berbagai kemudahan. (5) Menghindari belanja konsumtif. Belanja adalah hal yang sangat menyenangkan bagi setiap orang, pada saat bertemu dengan teman lama dan tetangga biasanya ada berbagai informasi dan tukar pendapat terkait belanja-belanja yang sama sekali tidak produktif bahkan terkadang barang yang dibeli merupakan barang yang sudah ada sebelumnya. Tetapi karena terdorong oleh nafsu belanja, barang tersebut dibeli dengan terburu-buru oleh kita padahal barang tersebut sangat tidak diperlukan. (6) Memiliki tujuan atau cita-cita finansial. Susunlan target keuangan keluarga yang akan dicapai, misalnya tahun 2021 sudah memiliki tabungan 50 juta di salah satu Credit Union (CU) dan beberapa tahun kedepan akan pensiun melalui tabungan yang sudah dipersiapkan serta anak-anak mendapatkan pendidikan yang layak serta dapat meraih gelar sarjana dan sebagainya. (7) Menabung, menabung, menabung. Mengubah pola pikir saat mendapatkan uang dengan ingat menabung minimal $10 \%$ dari penghasilan yang diterima dan diterapkan dengan disiplin. segera setelah menerima uang langsung menabung ke CU tanpa ditunda serta memisahkan tabungan untuk keperluan sehari-hari sengan tabbungan sebagai cadangan atau persiapan untuk pensium dan pendidikan anak (Beni \& Rano, 2017). (8) Berinvestasilah. Tentu Anda tak akan puas dengan hanya menunggu tabungan membumbung. Padahal cita-cita Anda untuk keluarga “selangit". Inilah saat yang tepat untuk juga memikirkan investasi. Kini bentuknya macam-macam. Takut akan risiko investasi?! Tak perlu khawatir, Anda hanya perlu belajar pada ahlinya. Konsultasikan keuangan Anda dengan ahli keuangan yang handal". 


\section{METODE}

Metode pelaksanaan kegiatan ini penyuluhan ini diawali dengan melakukan koordinasi dengan Bapak Apolius selaku Kepala Desa Bani Amas terkait rencana kegiatan penyuluhan untuk mendapatkan gambaran metode pelaksanaan dan materi yang cocok bagi peserta. Kegiatan selanjutnya membuat proposal kegiatan penyuluhan dan diseminasi rencana kegiatan yang difasilitasi oleh Pusat Riset dan Pengabdian Masyarakat Sekolah Tinggi Ilmu Manajemen Shanti Bhuana untuk dapat dibuatkan Surat Tugas (ST) kegiatan Pengabdian Kepada Masyarakat. Setelah selesai melakukan diseminasi dan mendapatkan surat tugas, tim melakukan persiapan dengan menyiapkan materi penyuluhan serta berkoordinasi dengan kepala desa Bani Amas terkait pembuatan undangan untuk peserta serta menentukan jadwal dan tempat pelaksanaan kegiatan penyuluhan yang dihadiri oleh masyarakat penerima bantuan Program Keluarga Harapan (PKH) atau yang disebut dengan istilah Keluarga Penerima Manfaat (KPM) di desa Bani Amas Kecamatan Bengkayang. Setelah selesai kegiatan, pada sesi 4 dilakukan tanya jawab dan evaluasi untuk mengetahui sejauh mana kegiatan membawa dampak dan menjawab permasalahan mitra.

\section{HASIL DAN PEMBAHASAN}

Kegiatan penyuluhan dilakukan selama 1 (satu) hari efektif di Aula Kantor Desa Bani Amas hari Jumat tanggal 28 Februari 2020 mulai pukul 10.30 WIB sampai pukul 15.00 WIB dengan pembagian materi sebagai berikut.

Tabel 1. Rincian Kegiatan

\begin{tabular}{clc}
\hline No & \multicolumn{1}{c}{ Keterangan } & Waktu \\
\hline 1 & Registrasi Peserta & $08.30-10.00$ WIB \\
\hline 2 & Doa Pembukaan & $10.00-10.15$ WIB \\
\hline 3 & Pembukaan: Kata Sambutan dari Kepala Desa & $10.15-10.30$ WIB \\
& Bani Amas (Bapak Apolius) sekaligus \\
& membuka kegiatan penyuluhan & \\
\hline 4 & Photo Bersama & $10.30-10.45$ WIB \\
\hline
\end{tabular}




\begin{tabular}{cll}
\hline No & \multicolumn{1}{c}{ Keterangan } & \multicolumn{1}{c}{ Waktu } \\
\hline 5 & Coffe Break & $10.45-11.00$ WIB \\
\hline 6 & Sesi 1 : Mengelola Keuangan Keluarga & $11.00-12.00$ WIB \\
\hline 7 & Istirahat & 12.00 .12 .30 WIB \\
\hline 7 & Sesi 2 : Cermat Meminjam dan Menabung & $12.30-13.30$ WIB \\
\hline 8 & Sesi 3 : Memulai Usaha & $13.30-14.30$ WIB \\
\hline 9 & Sesi 4 : Tanya Jawab dan Evaluasi & $14.30-15.00$ WIB \\
\hline 10 & Penutup: Kegiatan ditutup oleh Kepala Desa & $15.00-15.15$ WIB \\
\hline 11 & Pembacaan Doa Penutup & $15.15-15.30$ WIB \\
\hline 12 & Sayonara & 15.30 WIB \\
\hline
\end{tabular}

Secara umum materi dan pelaksanaan kegiatan penyuluhan setiap sesi sebagai berikut:

\section{Sesi 1 Mengelola Keuangan Keluarga}

Sesi ini diawali dengan memaparkan tujuan mempelajari materi yaitu: mengidentifikasi sumber pendapatan dan pengeluaran keluarga, serta menghitung rata-rata jumlah pendapatan pengeluaran, Peserta mampu menentukan prioritas pengeluaran dan menuliskannya dalam anggaran keuangan keluarga, Peserta memahami cara mengendalikan pengeluaran sesuai anggaran yang telah dibuat, sehingga kebutuhan keluarga dapat terpenuhi. Adapun langkah-langkah pelaksanaan sesi 1 sebagai berikut:

(1) Mengidentifikasi sumber pendapatan dan jenis pengeluaran keluarga

(2) Kegaiatan diawali dengan pertanyaan singkat apakah peserta mengalami masalah keuangan dimana pengeluaran seringkali lebih besar dari pemasukan? Jawaban umumnya adalah 'ya". Saat penyempaian materi dibuatkan yel-yel yang berbunyi demikian. Uang tidak Cukup, Seluruh peserta wajib menjawab: Ya Atur Dong...Sambil menggerakkan salah satu anggota badan.

(3) Menghitung jumlah pendapatan dan pengeluaran keluarga

(4) Memahami beda "Kebutuhan" dan "Keinginan" 
Peserta diajak berdiskusi terlebih dahulu untuk membedakan antar kebutuhan dan keingin. Setelah dilakukan diskusi untuk mengetahui pemahaman dan keadaan peserta tentang kebutuhan dan keinginan yang terjadi selama ini pada keluarga masing-masing, baru disampaikan atau dibahas materi sebagai berikut:

\begin{tabular}{|c|c|c|}
\hline JENIS PENGELUARAN & & IAWABAN \\
\hline Bayar listrik & \multicolumn{2}{|c|}{ Kebutuhan, untuk penerangan } \\
\hline Uang jajan & \multicolumn{2}{|c|}{$\begin{array}{l}\text { Keinginan, kalau bukan untuk membedi hal- } \\
\text { hal penting seperti bayar onqkos bus atau } \\
\text { makan siang }\end{array}$} \\
\hline Bayar utang & \multicolumn{2}{|c|}{$\begin{array}{l}\text { Kebututuan, ini adsleh kewajibari kepada } \\
\text { orang tain }\end{array}$} \\
\hline Tes baru & \multicolumn{2}{|c|}{ Keinginan, soidah purnya tas lain } \\
\hline Arisan & \multicolumn{2}{|c|}{$\begin{array}{l}\text { Kebutuhan, sebagai uang cadangan dan } \\
\text { juge merupakan kewajiban kepecta orarng } \\
\text { lain }\end{array}$} \\
\hline Beli miakanun dan susus & \multicolumn{2}{|c|}{ Kebutuhien, untuk asujpan nutrisi } \\
\hline $\begin{array}{l}\text { Perlengkapan mandi dan } \\
\text { cuci }\end{array}$ & \multicolumn{2}{|c|}{$\begin{array}{l}\text { Kebutuhan, perlu untuk kebersthan dan } \\
\text { kesechatan }\end{array}$} \\
\hline Tabungan & \multicolumn{2}{|c|}{ Kebutuhan, untuk berjaga-jago } \\
\hline Rokok & \multicolumn{2}{|c|}{ Keinginan, tidak mernberikan marifaat. } \\
\hline Puisa telpon: & \multicolumn{2}{|c|}{$\begin{array}{l}\text { Kebutuhan, kalau untuk mesmberi dan me- } \\
\text { nerims kabor penting. } \\
\text { Keingiruan, jiks digunakan untuk main-main }\end{array}$} \\
\hline \multicolumn{2}{|l|}{ KEBUTUHAN } & KEINGINAN \\
\hline \multicolumn{2}{|c|}{$\begin{array}{l}\text { - Harus dipenuhi segera } \\
\text { - Jika tidak dipenuhi akan ganggu } \\
\text { kehthidupan }\end{array}$} & $\begin{array}{l}\text { - Bisa ditunda } \\
\text { - Jika tidak diponuhi tidak } \\
\text { banyak memengarnahi ke- } \\
\text { langsungan hichup }\end{array}$ \\
\hline
\end{tabular}

Gambar 1. Perbandingan Kebutuhan dan Keinginan

(5) Menyusun prioritas untuk menyeimbangkan pengeluaran dan pendapatan.

(6) Menyusun ABK, peserta diajak untuk menyimak materi sebagai berikut:

\begin{tabular}{|c|c|}
\hline HOE 249 & Rondapotent \\
\hline Katwangin & Jumiab (AAe) \\
\hline Upah Bbu Lï: & No 100.000 \\
\hline Wpew Pat Rueil & Rpp 400.000 \\
\hline TOTAL PENCDARATAN GRPI & "np 6000.000 \\
\hline & Pengeluarant \\
\hline Keteriongan & Jumben (RP) \\
\hline Harg ievien Dewn: & App 7.500 . 24 hari $=$ Nen 36.000 \\
\hline Uang jejan Aguis & Wip $1.000 \times 29$ han $-D p 20.000$ \\
\hline Taburigan Dewei & Re 5.000 \\
\hline Sum its & ep 20.000 \\
\hline Tas thane Agyos & a) \\
\hline Meant & Rp 450.000 \\
\hline Latrit & $R=20.000$ \\
\hline Pulas wilpen & $\mu_{0}=70.000$ \\
\hline Perlengkayan mandi cuca & Rp. 25.000 \\
\hline Rokitat & a \\
\hline Expar utarivg & Rp 40.000 \\
\hline Arisen kentampok tawn & RP 20.000 \\
\hline Ansen PKK & App 10.000 \\
\hline TOTAL MENORLLARAN (Rp) & 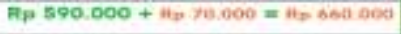 \\
\hline SELUSEH PENDAPATAN - PENGELUARAN & 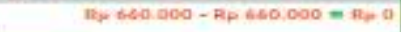 \\
\hline
\end{tabular}

Gambar 2. Contoh ABK 
(7) Memahami pentingnya menjalankan anggran yang telah dibuat.

(8) Mengetahui pilihan cara untuk mengendalikan pengeluaran.

(9) Membuat catatan kas harian $(\mathrm{CKH})$.

(10) Peserta diajak praktik langsung mengerjakan soal untuk meningkatkan pemahaman tentang pengeluaran keluarga, adapun contoh soal dapat dilihat pada gambar berikut ini.

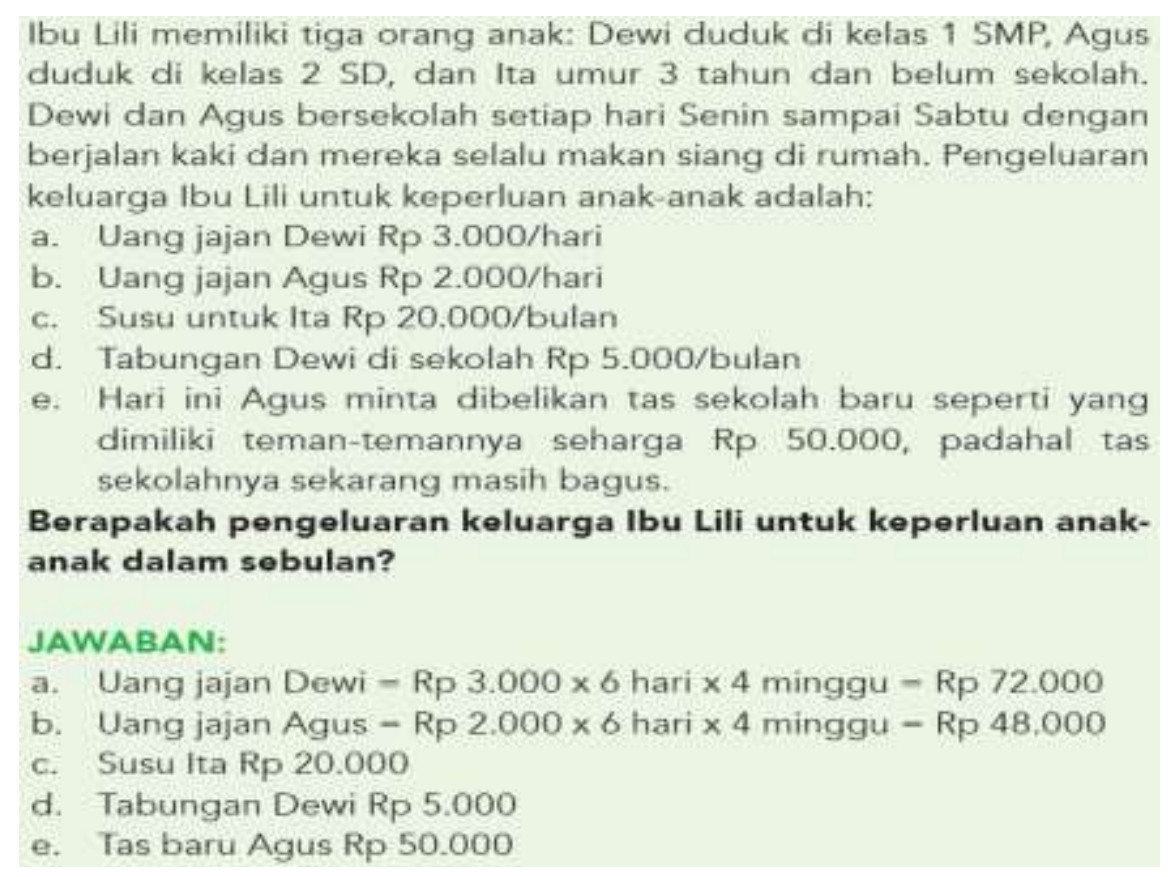

\section{Gambar 3. Contoh Soal}

Lalu, setelah mengerjakan soal secara bersama-sama peserta diajak untuk memberikan kesimpulan yakni: Salah satu cara agar pendapatan bisa mencukupi adalah dengan mengatur dan mengurangi pengeluaran yang tidak mendesak.

\section{Sesi 2 Cermat Meminjam dan Menabung}

Materi ini mengajak peserta untuk mengurangi ketergantungan terhadap Utang (termasuk berharap bantuan PKH Terus Menerus) dengan menabung. Penyampaian materi diawali dengan pertanyaan: Bagaimana peserta mengatasi kekurangan uang selama ini? Umumnya peserta menjawab berutang (uang dan barang di warung/took/toke) mengambil tabungan, atau berhemat. Dalam materi ini juga ditekankan bahwa berutang boleh saja dilakukan, tetapi harus dilakukan secara matang dan terencana dengan baik agar tidak terus tergantung utang 
(Kementerian Sosial, 2018). Dilajutkan dengan memberikan solusi tempat meminjam yang tidak merugikan dan dengan membiasakan menabung untuk mencegah berutang kembali. Peserta diajak untuk melihat materi berikut ini:

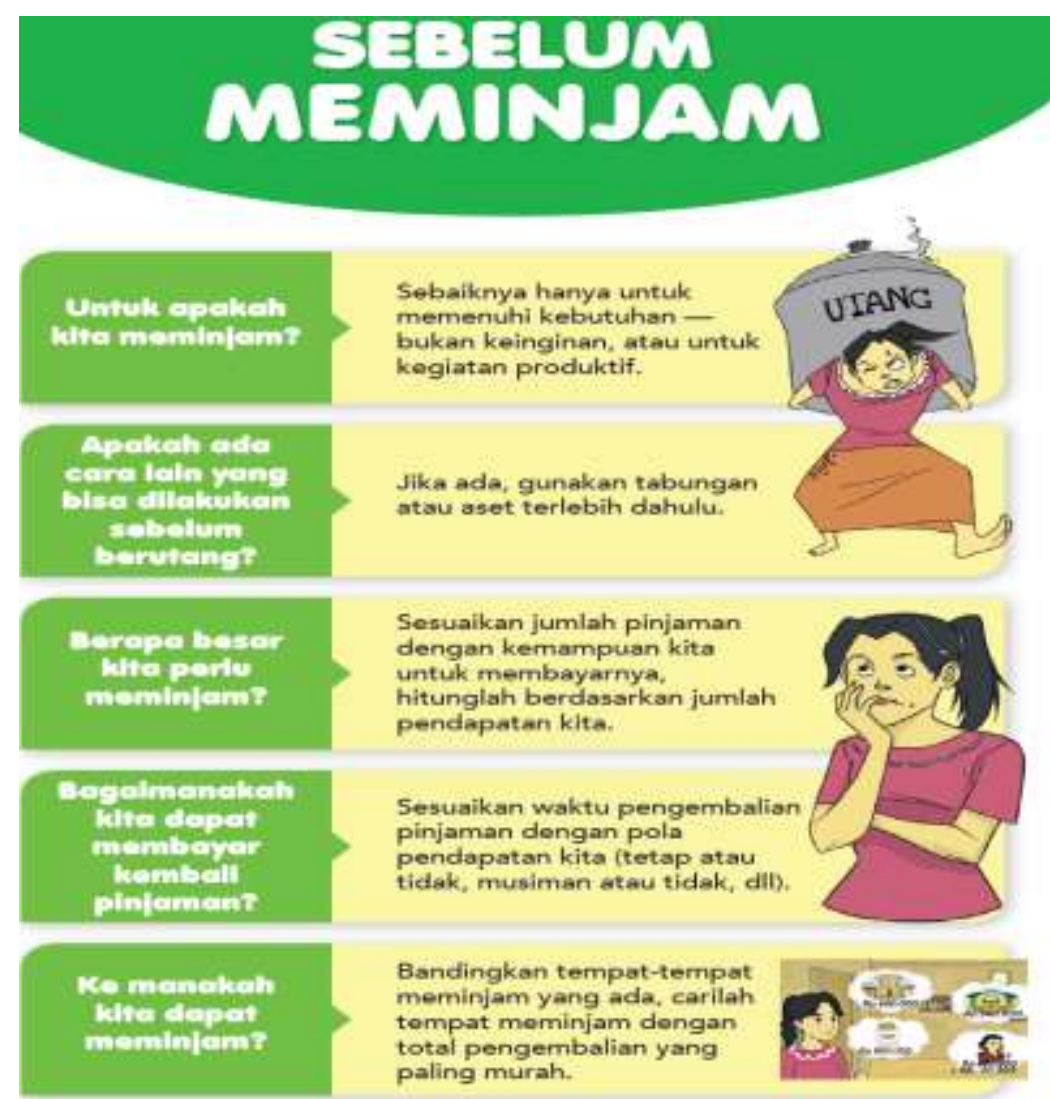

Gambar 4. Alur Berpikir Sebelum Meminjam

Peserta diajak untuk memahami jenis lembaga keuangan yang umum mereka gunakan. Beberapa lembaga keuangan resmi (berbadan hukum) yang biasanya memberikan pinjaman adalah: (1) Koperasi (Credit Union/CU), menghimpun dana dari anggota kemudian disalurkan kembali kepada anggota melalui pinjaman kepada anggota. Pinjaman hanya diberikan kepada anggota yang telah memenuhi persyaratan dan telah mengikuti Pendidikan Dasar, Pendidikan Kredit yang telah dipersyaratkan, dimana tabungan sebagai jaminannya. Untuk menjadi anggota CU, ada beberapa persyaratan yang harus dipenuhi sesuai dengan ADRT setiap CU seperti membayar Simpanan Wajib, Simpanan Pokok, Simpanan Sukarela, Iuran Tahunan (Kesehatan dan Sosial) serta Pendidikan. Adapun CU yang beroperasional dan sehat di Bengkayang : CU 
Bonaventura, CU Keluarga Kudus, CU Khatulistiwa Bakti, CU Pancur Kasih, CU Lantang Tipo, dan CU Semarong (Beni \& Rano, 2017). (2) Bank, menghimpun dana dari masyarakat dalam bentuk simpanan dan menyalurkannya kepada masyarakat dalam bentuk kredit dan lainnya sesuai persyaratan yang telah di tentukan. (Adapun Bank yang beroperasional di Bengkayang: BPD Kalbar, BRI, BNI, E-Batara Pos (BTN), dan Bank Mandiri).

Konsep menabung yang diajarkan adalah : Pendapatan $-10 \%$ Menabung $=$ Konsumsi. Konsep ini merupakan konsep menabung ala CU sesuai dengan buku "Membangun Manusia Melalui Pendidikan Dasar Credit Union” (Sabinus Beni, 2017). Serta diperkuat dalam artikel yang berjudul "Pengaruh Simpanan dan Tunggakan Kredit Terhadap Kesejahteraan Anggota Credit Union (Sabinus Beni, 2016).

\section{Sesi 3 Memulai Usaha}

Materi sesi ini dibagi menjadi beberapa sub materi antara lain: (1) mencari ide usaha. Diawali dengan pertanyaan kepada peserta, Apakah ada rencana membuka usaha? Jika ada, jawablah pertanyaan-pertanyaan berikut ini untuk merencanakannya dengan matang seperti: Adakah hasil alam atau kondisi lingkungan yang bisa dimanfaatkan? Keterampilan apakah yang tersedia? Usaha apakah yang akan dilakukan?. (2) Mengembangkan dan Menilai Kelayakan Usaha. Ide-ide usaha dikembangkan dengan menjawab pertanyaan-pertanyaan berikut: Siapakah target pembelinya? Bagaimanakah untung bisa didapat nanti? Jika pernah melakukan usaha, apakah penyebab kegagalan selama ini? Apa yang mendorong kemajuan usaha (Kekuatan, apa saja kelebihan usaha kita dibanding usaha lain yang sejenis?, Peluang, apa saja yang ada di luar usaha kita namun dapat memberikan pengaruh positif?), Apa yang menghambat kemajuan usaha (kelemahan, apa saja kekurangan usaha kita dibanding usaha lain yang sejenis?, Bagaimana cara mengatasi kelemahan? Ancaman: apa saja yang ada di luar usaha kita namun dapat memberikan pengaruh negatif? Bagaimana cara mengatasi ancaman?). semua pertanyaan-pertanyaan tersebut dijawab oleh peserta dalam sebuah catatan masing-masing peserta yang nantinya menjadi bekal untuk 
memulai usaha. (3) Merencanakan keuangan usaha. Kegiatan ini untuk memastikan usaha dapat memberikan keuntungan dengan mengisi anggaran keuangan usaha (Gambar 5).

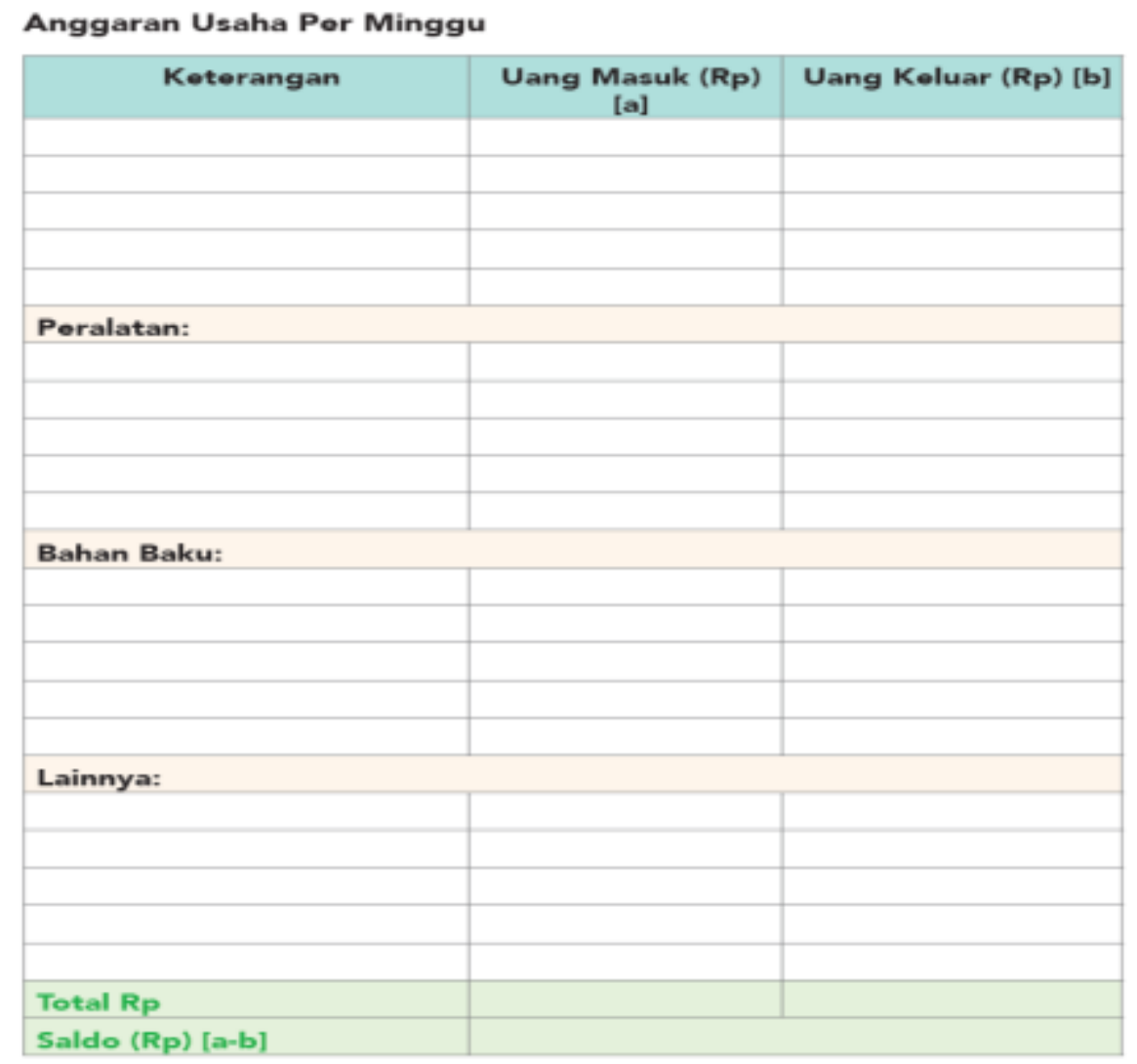

Gambar 5. Contoh Format Anggaran Usaha

(4) Merencanakan pemasaran. Untuk melatih peserta dalam menarik pelanggan, peserta diajak menjawab pertanyaan berikut: Barang/jasa seperti apa yang dibutuhkan pelanggan dan mampu bersaing dengan yang sudah ada, berapa harga jual yangbisa memberikan keuntungan dan bersaing dengan yangsudah ada, dimanakan tempat untuk menjual/membuat barang/jasa yang strategis, Promosi apa yang perlu dilakukan. (5) Mengelola keuangan usaha. Setelah usaha berjalan, catat seluruh pemasukan dan pengeluaran dalam catatan Kas Harian Usaha. Contoh Kas Harian Usaha disajikan pada Gambar 6. 


Catatan Kas Harian untuk Usaha (Bulan ........................)
\begin{tabular}{|l|l|l|l|l|}
\hline Tgl. & Keterangan & $\begin{array}{c}\text { Uang masuk } \\
(\text { RP) }\end{array}$ & $\begin{array}{c}\text { Uang keluar } \\
(\text { Rp) }\end{array}$ & Sisa (Rp) \\
\hline & & & & \\
\hline & & & & \\
\hline & & & & \\
\hline & & & & \\
\hline & & & & \\
\hline & & & & \\
\hline & & & & \\
\hline & & & & \\
\hline & & & & \\
\hline & & & & \\
\hline & & & & \\
\hline & & & & \\
\hline
\end{tabular}

Gambar 6. Contoh Format Kas Harian Usaha

\section{Sesi 4 Tanya Jawab}

Sesi terakhir dilakukan bagi peserta yang tertinggal dalam beberapa sesi (sesi 1-3) agar dapat dibantu oleh narasumber dan dibantu oleh peserta yang dianggap telah menguasai materi dan membantu peserta lainnya yang kesulitan, setelah selesai. Kegiatan ditutup oleh Kepala Desa Bani Amas.

Dari kegiatan diatas, hasil tanya jawab dan evaluasi diketahui bahwa 64 orang peserta yang terdiri dari 55 Keluarga Penerima Manfaat (KPM) Program Keluarga Harapan (PKH) dan 9 orang Aparatur Desa, sebanyak $71 \%$ atau 45 orang peserta memahami materi dan siap menerapkannya dalam kehidupan seharihari terutama dengan menabung minimal $10 \%$ dari total penghasilan dan ingin membuka kebun. Diantaranya kebun Jagung dan Sayuran untuk menambah penghasilan agar tidak bergantung pada bantuan PKH. Sebanyak 19 orang tidak atau belum memahami, hal tersebut dikarenakan beberapa diantaranya masih ingin 
berada pada zona nyaman menerima bantuan pemerintah. Dari presentase pemahaman peserta, kami berkesimpulan kegiatan ini menjawab apa yang menjadi permsalahan mitra, kedepannya Pemerintah Desa Bani Amas siap membantu dan menganggarkan dana pemberdayaan untuk kegiatan pendampingan usaha masyarakat di Desa Bani Amas melalui Anggaran Dana Desa.

Kegiatan penyuluhan ini juga sejalan dengan kegiatan yang telah dilakukan sebelumnya di Desa Setia Budi Kecamatan Bengkayang Tahun 2019 yang berjudul Penyuluhan dan Pengelolaan Keuangan Keluarga Penerima Manfaat Program Keluarga Harapan di Desa Setia Budi (Beni, Manggu, \& Sadewo, 2019). Kegiatan ini juga sejalan dengan kegiatan Bimbingan Teknis Koperasi se Kabupaten Bengkayang Tahun 2019 di Aula Tuah Raya yang dihadiri dan diikuti oleh pengawas koperasi se Kabupaten Bengkayang dan Petugas Penyuluh Koperasi Lapangan (Beni \& Manggu, 2019).

\section{SIMPULAN}

Kesimpulan dari kegiatan ini dapat penulis sampaikan beberapa kesimpulan, antara lain; Peserta kegiatan dihadiri oleh 55 Keluarga Penerima Manfaat KPM Program Keluarga Harapan dan 9 orang dari aparatur Desa Bani Amas, Peserta sangat antusias mengikuti materi terutama dalam pengelolaan keuangan keluarga yang dilanjutkan dengan perencanaan usaha, harapan peserta setelah kegiatan ini mereka dapat segera membuka usaha dan segera graduasi/keluar dari peserta $\mathrm{PKH}$ karena sudah mandiri, Kesulitan yang dialami KPM dalam mencari ide usaha karena mayoritas mereka belum menemukan mentor yang dapat membantu dan membina mereka dalam memulai dan mengelola usaha, Kelemahan dalam sistem administrasi juga dialami oleh seluruh peserta terutama dalam menyusun $A B K$, dikarenakan mayoritas memiliki pendidikan yang rendah (SD dan Pra SD). Dari kegiatan diatas menjawab tujuan diadakannya kegiatan penyuluhan ini dengan sasaran KPM dan Aparatur desa dimana semua KPM mengikuti kegiatan tersebut dan mayyoritas KPM akan berusaha menerapkan pola pengelolaan keuangan keluarga dengan disiplin menabun $10 \%$ dari penghasilan dan ingin membuka 
usaha khususnya kebun jagung agar tidak terus menerus bergantung kepada bantuan dan uluran tangan pemerintah melalui Program Keluarga Harapan (PKH).

Beberapa rekomendasi yaitu: perlu dilakukannya kegiatan serupa secara rutin oleh pihak desa melalui dana desa dan alokasi dana desa untuk pembinaan usaha produktif masyarakat dengan mencari mentor/pengusaha lokalyang bersedia diajak bermitra serta mengadakan pendidikan non formal (program kejar paket A, $\mathrm{B}$, dan $\mathrm{C}$ yang di subsidi dari dana desa dan alokasi dana desa.

\section{UCAPAN TERIMA KASIH}

Ucapan terima kasih kami sampaikan kepada Pusat Riset dan Pengabdian Masyarakat Sekolah Tinggi Ilmu Manajemen Shanti Bhuana yang telah memfasilitasi kegiatan ini melalui anggaran Pengabdian Pada Masyarakat Tahun 2020. Penghargaan setinggi-tingginya juga kami sampaikan kepada Pemerintah dan Masyarakat Desa Bani Amas yang ikut berpartisipasi dalam pelaksanaan kegiatan serta pihak-pihak tidak dapat kami sebutkan satu persatu yang berkontribusi dalam upaya mensukseskan kegiatan penyuluhan hingga berjalan dengan sukses.

\section{DAFTAR PUSTAKA}

Apolius. (2019). Permasalahan penduduk miskin penerima bantuan PKH di Desa Bani Amas. Bengkayang.

Beni, S. (2016). Pengaruh Simpanan dan tunggakan kredit terhadap kesejahteraan anggota credit union (studi kasus koperasi kredit CU Lantang Tipo). Prosiding seminar nasional fe universitas terbuka, VIII (challange and strategy faculty economicsand businessin digital era), 333-339. (Online), (repository.ut.ac.id).

Beni, S. (2017). Buku Pembangunan manusia melalui pendidikan dasar credit union. (Herulono, Ed.) (1st ed.). Jakarta: Mer-C Publishing Jakarta.

Beni, S., \& Manggu, B. (2019). Bimbingan teknis pengawasan koperasi sekabupaten Bengkayang tahun 2019: Manajemen pengawasan koperasi. PengabdianMu, 5(1), 67-71.

Beni, S., Manggu, B., \& Sadewo, Y. D. (2019). Cunseling of family financial management literacy program keluarga harapan beneficiaries. Diseminasi, 1(2), 83-88.

Beni, S., Manggu, B., \& Sensusiana. (2018). Modal Sosial sebagai suatu aspek dalam rangka pemberdayaan masyarakat. JURKAMI, 3(1), 8-24. (Online), (http://jurnal.stkippersada.ac.id/jurnal/index.php/JPE/article/view/341). 
Beni, S., \& Rano, G. (2017). Credit Union sebagai penggerak ekonomi masyarakat dayak Kalimantan Barat. Prosiding International Congress I Dayak Culture 1, 1(1), 168-177.

BPS. (2019). Kabupaten Bengkayang dalam angka 2019. (BPS, Ed.) (2019th ed.). Bengkayang: BPS Kabupaten Bengkayang.

Kementerian Sosial, R. (2018). Modul pengelolaan keuangan dan perencanaan usaha. (K. S. R. I. Program Keluarga Harapan, Ed.) (1st ed.). Jakarta: Kementerian Sosial. 